$\mathrm{M}$

едицинские клеточные технологии в терапии больных рецессивным дистрофическим буллезным Эпидермолизом. Метод внутрикожного введения фибробластов

\author{
В. И. Альбанова, А. Э. Карамова, В. В. Чикин, А. А. Минеева
}

ФГБУ «Государственный научный центр дерматовенерологии и косметологии» Минздрава России 107076, Москва, ул. Короленко, д. 3, стр. 6.

Рецессивный дистрофический буллезный эпидермолиз (РДБЭ) - тяжелое наследственное заболевание, в основе которого лежит генетически обусловленное нарушение синтеза фрибробластами коллагена VII типа. Недостаточная продукция коллагена VII типа и нарушение формирования якорных фрибрилл ослабляют прочность сцепления эпидермиса и дермы, что клинически выражается образованием пузыря или эрозии при малейшей механической травме. Основной источник коллагена VII типа в коже — фибробласты и кератиноциты. Использование аллогенных фибробластов является перспективным направлением клеточной терапии больных РДБЭ. Терапевтический эфффект внутрикожного введения фрибробластов обусловлен высокой стабильностью вновь синтезированного коллагена VII типа и его способностью фрормировать якорные фрибриллы в зоне дермо-эпидермального соединения. Результаты экспериментальных и клинических исследований свидетельствуют о возможности увеличения содержания коллагена VII типа в зоне дермо-эпидермального соединения и заживления длительно существующих дефектов кожи у больных РДБЭ методом внутрикожного введения аллогенных фрибробластов.

Ключевые слова: дистрофический врожденный буллезный эпидермолиз, терапия, аллогенные фибробласты.

Контактная информация: chikin@cnikvi.ru. Вестник дерматологии и венерологии 2015; (3): 46_53. 


\title{
Medical cell technologies for treatment of patients suffering from recessive dystrophic epidermolysis bullosa. Method of intracutaneous administration of fibroblasts
}

\author{
V.I. Albanova, A.E. Karamova, V.V. Chikin, A.A. Mineyeva
}

State Research Center of Dermatovenereology and Cosmetology, Ministry of Healthcare of the Russian Federation Korolenko str., 3, bldg 6, Moscow, 107076, Russia

\begin{abstract}
Recessive dystrophic epidermolysis bullosa (RDEB) is a severe inherited disease developing due to genetic abnormalities in the synthesis of Type VII collagen by fibroblasts. A low production rate of Type VII collagen and abnormalities related to the formation of anchoring fibrils weaken the epidermis and derma adhesion strength, which results in the formation of blisters or erosions in case of any mechanical injury. Fibroblasts and keratinocytes belong to the key sources of Type VII collagen in the skin. Application of allogeneic fibroblasts is a promising cell technique for treating RDEB patients. The therapeutic effect of fibroblasts intradermal administration is stipulated by high stability of newly synthesized Type VII collagen and its ability to form anchoring fibrils in the area of the dermoepidermal junction. According to experimental and clinical studies, it is possible to boost the content of Type VII collagen in the dermoepidermal junction area and heal long-term skin defects in RDEB patients by means of intradermal administration of allogeneic fibroblasts.
\end{abstract}

Key words: recessive dystrophic epidermolysis bullosa, therapy, allogeneic fibroblasts. 
Наследственный буллезный эпидермолиз (наследственная пузырчатка, механобуллезная болезнь) представляет собой группу моногенных заболеваний, включающую около 30 генотипических и фенотипических форм, обусловленных нарушением синтеза структурных белков эпидермиса или дермо-эпидермального соединения [1].

Одна из наиболее тяжело протекающих фрорм буллезного эпидермолиза - рецессивный дистрофический буллезный эпидермолиз (РДБЭ) - вызывается мутациями гена COL7A1, кодирующего белок коллаген VII типа. K настоящему времени описано около 730 мутаций гена COL7A1, обусловливающих широкий круг клинических френотипов [2]. Клинические проявления болезни могут существенно различаться даже у пациентов с одной и той же мутацией COL7A1: от локализованных высыпаний до генерализованных поражений кожи и слизистых оболочек с высоким риском развития плоскоклеточного рака [3].

\section{Патогенез РДБЗ}

Уменьшение продукции коллагена VII типа в результате мутаций гена COL7A1 обусловливает значительное снижение содержания или полное отсутствие якорных фрибрилл в зоне дермо-эпидермального соединения [4, 5]. Недостаточная продукция коллагена VII типа и нарушение формирования якорных фрибрилл ослабляют прочность сцепления эпидермиса и дермы, что клинически выражается образованием пузыря или эрозии при малейшей механической травме. У больных дистрофрическим врожденным буллезным эпидермолизом содержание якорных фрибрилл в зоне дермоэпидермального соединения составляет от 0 до 33\% от нормального уровня [6].

Коллаген VII типа якорных фрибрилл не только выполняет функцию сцепления эпидермиса и дермы, но и влияет на процессы формирования соединительной ткани, уменьшая выраженность фриброза и рубцевания [7]. Поэтому в условиях дефицита коллагена VII типа заживление дефектов кожи у больных РДБЭ происходит с явлениями рубцевания и фиброза [8]. Сцепление вновь сформированного эпидермиса с подлежащей дермой ослабляется, поэтому кожа в местах, где прежде были пузыри, легко эрозируется при малейшей травме. Эти участки кожи становятся излюбленными местами образования пузырей.

Рубцевание в последующем приводит к развитию у больных РДБЭ псевдосиндактилий, контрактур с нарушением фрунцций кистей, стриктур пищевода, дыхательных путей, мочевыводящих путей. В результате поражения кожи и слизистых оболочек желудочно-кишечного тракта развиваются синдром мальабсорбции, анемия, задержка роста. Характерно развитие ониходистрофии и потеря ногтей. У больных РДБЭ отмечен высокий риск развития плоскоклеточного рака кожи [9].

\section{Лечение больных РДБЗ}

Дефекты кожи, возникающие при РДБЭ, предрасположены ко вторичному инфицированию, болезненны, ограничивают движения, заживают с образованием атрофических рубцов. Лечение больных РДБЭ включает симптоматическую терапию, нацеленную на заживление периодически образующихся дефектов кожи с использованием лекарственных препаратов ранозаживляющего действия и раневых покрытий, терапию осложнений заболевания, уход за кожей, предупреждение воздействия факторов окружающей среды, способных вызывать образование пузырей [8]. Новым терапевтическим подходом, основанным на восстановлении экспрессии коллагена VII типа в коже больных, являются методы клеточной терапии с применением нескольких видов клеток - кератиноцитов, эндотелиальных клеток, полипотентных стволовых клеток, генетически модифицированных фибробластов, заменителей кожи $[10,11]$.

Целью клеточной терапии при дистрофическом буллезном эпидермолизе является заживление дефектов кожи и предупреждение их образования в последующем за счет повышения количества коллагена VII типа в зоне базальной мембраны [10].

Основным источником коллагена VII типа в коже являются фрибробласты и кератиноциты [12]. M. Goto и соавт. (2010) показали более выраженное увеличение содержания коллагена VII типа в зоне дермо-эпидермального соединения после введения фрибробластов, чем после пересадки кератиноцитов [13]. В связи с этим перспективным направлением клеточной терапии больных РДБЭ представляется использование аллогенных фибробластов.

Фибробласты - мезенхимальные клетки дермы, продуцирующие разные типы коллагена (в том числе и коллаген VII типа), эластин и внеклеточный матрикс. В коже существует несколько популяций фрибробластов, различающихся по фризической характеристике и функциональным возможностям, - фрибробласты волосяного фолликула, сетчатого слоя (ретикулярные) и сосочкового слоя (папиллярные) дермы. Функциональные различия популяций фрибробластов заключаются в синтезе проколлагена (он синтезируется преимущественно ретикулярными фрибробластами) и различных растворимых фракторов. Папиллярные фибробласты усиливают эпидермальную дифференцировку, участвуют в образовании базальной мембраны, препятствуют образованию рубца (оказывают антифибротическое действие) [14]. Ретикулярные фибробласты, наоборот, подавляют дифференцировку кератиноцитов и формирование зоны базальной мембраны, способствуют образованию рубца (профибротическое действие) [15-18]. Показано, что искусственный аналог кожи, полученный с использованием кератиноцитов и папиллярных фибробластов, харак- 
теризуется более высокой экспрессией дермо-эпидермальных адгезивных и якорных белков по сравнению с аналогом кожи, содержащим кератиноциты и ретикулярные фрибробласты [19]. Поэтому предполагается, что селективное использование папиллярных фрибробластов в клеточной терапии больных с заболеваниями, сопровождающимися дефектами базальной мембраны, в том числе наследственным буллезным эпидермолизом, может улучшить результаты лечения [19]. Благоприятный эфрфект действия фрибробластов на заживление дефектов кожи может быть также связан с тем, что выработка этими клетками матриксных металлопротеиназ МMP-9 и МMP-13 в процессе репарации может обеспечить заживление без фрормирования рубцов [20]. Следует также учитывать, что фрибробласты обладают региональной специфичностью. Предполагается, что фрибробласты «запоминают» свое расположение в организме и исполняют соответствующие функции при пересадке в другое место [21].

Фибробласты являются более простыми для культивирования, чем кератиноциты, сохраняют в культуре диплоидный кариотип, имеют низкую экспрессию антигенов гистосовместимости после пассирования и характеризуются отсутствием онкогенного потенциала, что позволяет использовать культивируемые in vitro фрибробласты человека в терапевтических целях [22, 23]. Низкая иммуногенность позволяет использовать для пересадки аллогенные фрибробласты, полученные от неродственного пациенту донора. В отношении аллогенных фрибробластов существует возможность быстрой наработки большого количества относительно недорогого клеточного материала, его криоконсервации и хранения больших запасов клеток для их срочного применения [23].

Использование для пересадки собственных фрибробластов больного РДБЭ нецелесообразно, так как при этом заболевании они продолжают продуцировать дефектные белки, а скорость пролиферации фибробластов у больных РДБЭ снижена по сравнению с фрибробластами нормальной кожи и продолжает снижаться с возрастом. Кроме того, при РДБЭ у фрибробластов снижается способность к одному из защитных механизмов выживания клеток - аутофрагии, представляющей собой процесс, при котором внутренние компоненты клетки доставляются внутрь ее лизосом и подвергаются в них деградации [24, 25].

K настоящему времени проведено небольшое число экспериментальных исследований, в которых оценивались результаты внутрикожного введения нормальных фрибробластов и фрибробластов с корректированным геном Col7a1 мышам - модели РДБЭ и клинических исследований с участием небольшого числа больных РДБЭ.
Экспериментальные исследования эффективности и безопасности клеточной терапии методом внутрикожного введения фибробластов

Первые экспериментальные исследования по оценке эфффективности продукции коллагена VII типа пересаженными человеческими фрибробластами были проведены с использованием иммунодефицитных мышей и мышей, которым трансплантировали эквивалент кожи человека с РДБЭ. Эти эксперименты позволили определить эффрективную дозу пересаженных фибробластов: внутрикожное введение $1 \cdot 10^{6}$ фиибробластов не приводило к повышению экспрессии коллагена VII типа [26]. Повышение экспрессии коллагена VII типа в зоне дермо-эпидермального соединения и фрормирование якорных фибрилл наблюдалось после введения $5 \cdot 10^{6}$ фибробластов [27]. Показано, что синтезированный после инъекции фииробластов коллаген VII типа сохраняется в дермо-эпидермальном соединении кожи мышей в течение длительного времени - от нескольких недель до нескольких месяцев [27].

Для более точной оценки эфрфективности и безопасности внутрикожного введения фрибробластов была создана животная модель дистрофического буллезного эпидермолиза - Col7a1-гипоморфные мыши, у которых уровень экспрессии коллагена VII типа в коже составляет 10\% от нормального [5]. Фенотип этих мышей близок проявлениям РДБЭ у человека и характеризуется образованием пузырей в местах незначительного травмирования кожи, прогрессирующей дистрофией когтей и рубцовыми деформациями конечностей.

В эксперименте мышам - модели РДБЭ в выбранную область спины размером 1,5 × 2,5 см были введены внутрикожно человеческие фрибробласты в дозе 20 млн клеток в 0,5 мл физиологического раствора. Через 7 дней процедуру введения фибробластов повторили. Отмечено, что в течение 7 дней после инъекции у мышей уменьшалось количество образующихся пузырей. Этот эфффект сохранялся на протяжении 70 дней, после чего склонность к образованию пузырей увеличилась, однако до 100-го дня после инъекции число образующихся пузырей было меньше, чем до лечения [28].

Использование фииробластов, экспрессирующих зеленый флюоресцирующий белок (EGFP+), позволило контролировать жизнеспособность и миграцию введенных клеток. Обнаружено, что через 24 ч после второй инъекции EGFP+ фибробласты располагались во всех слоях дермы мышей. Большинство введенных фибробластов оставалось в пределах участка кожи, в который была проведена инъекция, однако наблюдалась их незначительная миграция в прилегающие участки дермы. Морфометрические измерения выявили, что клетки не перемещаются на расстояние более 10 мм от места введения. 
Отсутствие экспрессии в дерме мышей маркера пролиферации клеток - белка Ki67 показало, что введенные внутрикожно фрибробласты после инъекции не пролиферируют. Через 28 дней после введения EGFP+ фрибробласты в дерме не обнаруживались, что свидетельствует об апоптозе фибробластов.

Повышение экспрессии МРНК и белка коллагена VII типа было выявлено через 7-21 день после повторного внутрикожного введения фрибробластов в дерме мышей. Уровень мРHK коллагена VII типа возвращался к исходному через 28 дней, что говорит о прекращении синтеза белка в эти сроки. Синтезированный после введения фрибробластов коллаген оставался стабильным более продолжительное время. Через 70 дней после введения фибробластов уровень флюоресценции коллагена VII типа в коже мышей был в 4,7 раза выше, чем в участке кожи, в который не вводили фрибробласты, через 100 дней - в 3,5 раза выше, через 120 дней - в 2 раза выше [28].

Через 70 дней после введения фрибробластов в зоне дермо-эпидермального соединения кожи мышей были обнаружены волокнистые структуры, что указывает на способность образовавшегося коллагена VII типа образовывать фрибриллы и выполнять свои функции [28].

Небольшое повышение экспрессии коллагена VII типа в коже мышей - модели РДБЭ, у которых экспрессия этого белка составляет лишь 10\% от нормального уровня, приводит к значительному увеличению резистентности кожи к механическим воздействиям и улучшению фенотипа [5]. Показано, что 3,5-кратное увеличение содержания коллагена VII типа в коже (примерно до 35\% от нормального уровня) через 100 дней после инъекции все еще обеспечивает коже достаточную устойчивость при механических нагрузках. В связи с этим предполагается, что полное восстановление экспрессии коллагена VII типа не является обязательным для улучшения фрункций якорных фрибрилл и повышения устойчивости кожи к механическим воздействиям. Однако двукратное увеличение содержания коллагена VII типа в коже (примерно до 20\% от нормального уровня), отмеченное на 120-й день после введения фибробластов, не обеспечивало ее.

Безопасность введения аллогенных фибробластов мышам подтверждается отсутствием развития специфического иммунного ответа и продукции антител к коллагену VII типа [28]. После введения фрибробластов экспрессия участвующих в развитии фиброза трансформирующего фрактора роста- $\beta$, срактора роста соединительной ткани (маркеры паракринной стимуляции, повышения продукции белков внеклеточного матрикса и начала фиброза), $\alpha$-гладкомышечного актина (маркер дифференцировки фибробластов в миофрибробласты и развития фриброза) и тенасцина С (ин- дикатор синтеза компонентов внеклеточного матрикса) не повышалась [28].

\section{Клинические исследования эффективности и безопасности лечения больных РДБЭ аллогенными фибробластами}

В нескольких клинических исследованиях I и II фразы оценена эфффективность и безопасность терапии больных РДБЭ методом внутрикожного введения аллогенных фибробластов. Для большинства исследований фибробласты получали из кожи крайней плоти младенцев [29-31], и лишь в одном исследовании использовали фрибробласты, полученные из кожи 23-летнего мужчины [32].

В клинических исследованиях с участием больных РДБЭ использовали препарат аллогенных

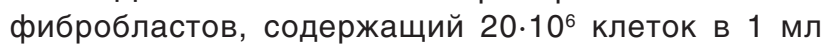
$[31,32]$. Внутрикожное введение аллогенных фрибробластов осуществляли однократно в различные участки кожи [29-32]. В клиническом исследовании I фразы T. Wong и соавт. (2008) для инъекций больным РДБЭ выбирали интактный участок кожи без пузыря и в выбранное место вводили 5.106 фрибробластов в 350 мкл (500 мкл - для одной пациентки) фросфатно-солевого буфрера [29]. В клиническом исследовании II фразы S. Venugopal и соавт. (2013) вводили препарат фрибробластов в дно длительно (не менее 3 мес.) существующих эрозий в объеме

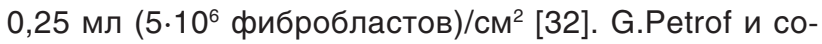
авт. (2013) вводили фрибробласты в края эрозий в количестве $5 \cdot 10^{6}$ фиибробластов на 1 см длины края эрозии [31].

В качестве контроля использовали препарат собственных (аутологичных) фрибробластов больных РДБЭ [29], фризиологический раствор [30], препарат HypoThermosol-FRS [31], препарат на основе альбумина [32].

Положительный эффрект отмечался уже через 7 дней после однократного внутрикожного введения аллогенных фрибробластов: значительно снизилось время заживления эрозий. Уменьшение площади эрозий, в края которых вводили фрибробласты, было более значительным по сравнению с контрольными эрозиями, по краям которых вводили основу для использовавшегося препарата аллогенных фибробластов [31]. S. Venugopal и соавт. (2013) показали, что эрозии уменьшились в размерах через 2 нед. как после введения фибробластов, так и после введения контрольного препарата [32].

Эпителизация эрозий у больных РДБЭ после введения фрибробластов сопровождалась повышением уровня экспрессии гена COL7A1 и белка коллагена VII типа [32]. У одного больного РДБЭ через 15 дней после введения фрибробластов экспрессия гена COL7A1 была повышена более чем в 20 раз. Уровень экспрессии коллагена VII типа через 2 нед. после 
введения аллогенных фрибробластов увеличивался в 1,5-2 раза, в то время как после введения собственных фрибробластов больного РДБЭ - не изменялся [29, 30]. S. Venugopal и соавт. (2013) также отметили повышение экспрессии коллагена VII типа через 2 нед. после введения фрибробластов у 3 из 5 пациентов. У 2 пациентов повышения его экспрессии не произошло, хотя уменьшение площади эрозии было отмечено. Различия в динамике заживления эрозий после введения фрибробластов и контрольного препарата обнаружены не были [32].

Повышение экспрессии коллагена VII типа у больных РДБЭ сопровождалось формированием якорных фрибрилл в зоне дермо-эпидермального соединения, что обнаруживалось после введения как фрибробластов, так и контрольного препарата [29, 32]. Количество якорных фрибрилл у больных увеличилось в 1,5 раза, однако по своей морфологии новые фрибриллы отличались от нормальных тем, что не имели перекрестного связывания в центре и отчетливого веерообразного вида, и поэтому напоминали незрелые якорные фрибриллы больных РДБЭ [29]. При патоморфологическом исследовании было отмечено уменьшение образования пузырей в коже больных РДБЭ в месте инъекции [29]. Однако сами фибробласты через 2 нед. и после инъекции в коже не определялись [29].

После 28-го дня наблюдения достигнутый клинический эффрект терапии методом внутрикожного введения аллогенных фибробластов сохранялся, но не отличался от результатов введения контрольного препарата НуроThermosol-FRS [31].

В последующие 4-6 мес. как после введения фрибробластов, так и после введения контрольного препарата отмечалось улучшение состояния эрозий вплоть до полного заживления [31, 32]. Кроме того, улучшение выражалось в уменьшении склонности к отделению эпидермиса при травме [29]. Патоморфологическое исследование кожи больных РДБЭ также показало сохранение терапевтического эффекта введения фрибробластов в эти сроки, что выражалось в уменьшении числа образующихся пузырей [29]. Во многих случаях в течение 12 мес. после введения фрибробластов появления новых эрозий в месте инъекций не отмечалось [32].

Экспрессия гена COL7A1 в коже одного больного РДБЭ после введения фииробластов через 90 дней была повышена более чем в 20 раз, но через 180 дней возвращалась к исходному уровню [30]. Экспрессия коллагена VII типа в зоне дермо-эпидермального соединения, по данным S. Venugopal и соавт. (2013), после инъекции нарастала и достигала максимума через 3 мес. [32]. В исследовании Т. Wong и соавт. (2008) через 3 мес. после введения фрибробластов повышение экспрессии коллагена в зоне дермо-эпидермального соединения сохранялось лишь у тех
3 из 5 больных РДБЭ, у которых исходный уровень коллагена VII типа был более высоким [29]. Через 270 дней после введения фибробластов, по данным N. Nagy и соавт. (2011), обследовавших одного больного РДБЭ, экспрессия коллагена VII типа оставалась повышенной, но через 360 дней возвращалась к исходному уровню [30].

Для повышения эфффективности лечения больных РДБЭ методом пересадки аллогенных фибробластов возможно проведение дополнительной терапии, способствующей заживлению эрозий. В экспериментах обнаружено, что процесс заживления дефектов кожи может быть усилен электростимуляцией [33]. Известен заживляющий эффрект препаратов на основе алоэ вера. Показано, что пероральный прием препарата алоэ вера (Aloe sterols) стимулирует синтез коллагена и гиалуроновой кислоты дермальными фибробластами [34].

Серьезных нежелательных явлений зарегистрировано не было. Отмечались нежелательные явления, развивавшиеся после введения фибробластов. С процедурой введения было связано развитие локальных нежелательных явлений - боли, эритемы, зуда [31]. Только у одного пациента на месте введения аллогенных фибробластов отмечались слабая эритема и зуд, которые исчезли спонтанно без лечения в течение недели. У одного пациента через 2 нед. на месте введения аллогенных фрибробластов появился незначительно выраженный гипертрофический рубец. Антитела к коллагену VII типа обнаружены не были.

Остаются нерешенными вопросы о механизме терапевтического действия аллогенных фрибробластов. Считается, что введенные аллогенные фрибробласты продуцируют нормальный коллаген VII типа, который формирует нормальные якорные фибриллы и способствует заживлению эрозий. Однако вновь образованные после внутрикожного введения фрибробластов якорные фрибриллы оставались патологически измененными. Кроме того, улучшение состояния больных РДБЭ наблюдалось также после введения препарата-основы, не содержащего клеточного материала, что свидетельствует о повышении синтеза коллагена VII типа за счет активации собственных фрибробластов пациентов и продукции ими фракторов роста [30].

Повышение экспрессии гена COL7A1 и синтеза коллагена VII типа после введения аллогенных фрибробластов сопровождается увеличением экспрессии гена $H B-E G F$ и продукции гепаринсвязывающего фактора роста, подобного эпидермальному фактору роста (HB-EGF), который повышает экспрессию гена COL7A1 [30]. Предполагается, что после внутрикожного введения фиибробластов развивается субклиническое воспаление, во время которого повышается продукция HB-EGF собственными кератиноцитами 
больного РДБЭ, что аутокринно поддерживает экспрессию гена COLTA1 на протяжении длительного времени [35, 36].

\section{Заключение}

Результаты экспериментальных и клинических исследований свидетельствуют о возможности увеличения содержания коллагена VII типа в зоне дермоэпидермального соединения и заживления длительно существующих дефектов кожи у больных РДБЭ методом внутрикожного введения аллогенных фрибробластов. Терапевтический эффект внутрикожного введения фибробластов обусловлен высокой стабильностью вновь синтезированного коллагена VII типа и его способностью фрормировать якорные фрибриллы в зоне дермо-эпидермального соединения. При этом для достижения выраженного терапевтического эффректа и повышения качества жизни больных не требуется полного восстановления экспрессии коллагена VII типа. Подтверждением этого служит отсутствие проявлений РДБЭ у гетерозиготных носителей рецессивно наследуемых нулевых мутаций гена COL7A1, у которых экспрессия коллагена VII типа coставляет 50\% от нормального уровня [28]. Поскольку в коже больных дистрофическим буллезным эпидермолизом содержание якорных фрибрилл снижено до 0-33\% [6], предполагается, что для поддержания механической стабильности кожи необходимо $\geq 35 \%$ уровня фризиологического коллагена VII типа и достижение этого уровня должно быть целью клеточной терапии больных дистрофическим буллезным эпидермолизом [28].

Терапия больных РДБЭ методом внутрикожного введения аллогенных фрибробластов не сопровождалась развитием серьезных нежелательных явлений. Проведение процедуры было сопряжено с болезненностью в месте инъекции, что требует предварительной местной анестезии. Следует учитывать возможность развития фиброза в месте введения фибробластов. Образования антител к коллагену VII типа после введения фрибробластов у больных РДБЭ отмечено не было.

В терапии важное значение имеет происхождение фибробластов, из которых был получен препарат. Введение папиллярных фибробластов может быть более эффрективным, имеют значение также регионарные особенности происхождения фрибробластов. Для улучшения выработки коллагена VII типа введенными фрибробластами могут использоваться различные методы их активации.

Таким образом, клеточная терапия больных РДБЭ методом внутрикожного введения аллогенных фибробластов представляет собой перспективное направление регенеративной медицины, позволяющее достигать максимально возможных на данный момент результатов лечения. I

\section{Литература}

1. Fine J.D. Inherited epidermolysis bullosa. Orphanet J Rare Dis. 2010; 5: 12.

2. Wertheim-Tysarowska K., Sobczyska-Tomaszewska A., Kowalewski C. et al. The COL7A1 mutation database. Hum Mutat 2012; 33: 327-331.

3. Kern J. S., Grüninger G., Imsak R. et al. Fortytwo novel COL7A1 mutations and the role of a frequent single nucleotide polymorphism in the MMP1 promoter in modulation of disease severity in a large European dystrophic epidermolysis bullosa cohort. Br J Dermatol 2009; 161 (5): 1089-1097.

4. Heinonen S., Männikkö M., Klement J. F. et al. Targeted inactivation of the type VII collagene gene (Col7a1) in mice results in severe blistering phenotype: a model for recessive dystrophic epidermolysis bullosa. J Cell Sci 1999; 112: 3641-3648.

5. Fritsch A., Loeckermann S., Kern J. S. et al. A hypomorphic mouse model of dystrophic epidermolysis bullosa reveals mechanisms of disease and response to fibroblast therapy. J Clin Invest 2008; 118: 1669-1679.
6. Tidman M. J., Eady R. A. Evaluation of anchoring fibrils and other components of the dermal-epidermal junction in dystrophic epidermolysis bullosa by a quantitative ultrastructural technique. J Invest Dermatol 1985; 84: 374—377.

7. Wang X., Ghasri P., Amir M. et al. Topical application of recombinant type VII collagen incorporates into the dermal-epidermal junction and promotes wound closure. Mol Ther 2013; 21 (7): 1335-1344.

8. Kern J. S., Has C. Update on diagnosis and therapy of inherited epidermolysis bullosa. Exp Rev Dermatol 2008; 3: 721_733.

9. Fine J.D., Johnson L. B., Weiner M. et al. Epidermolysis bullosa and the risk of life-threatening cancers: the National EB Registry experience, 1986-2006. J Am Acad Dermatol 2009; 60 (2): 203-211.

10. Yan W. F., Murrell D. F. Fibroblast-based cell therapy strategy for recessive dystrophic epidermolysis bullosa. Dermatol Clin 2010; 28 : 367-370.

11. Vanden Oever M. J., Tolar J. Advances in understanding and treating dystrophic epidermolysis bullosa. F1000Prime Reports 2014, 6: 35.
12. Konig A., Bruckner-Tuderman L. Transforming growth factor-beta stimulates collagen VII expression by cutaneous cells in vitro. J Cell Biol 1992; 117: 679—685.

13. Goto M., Sawamura D., Ito K. et al. Fibroblasts show more potential as target cells than keratinocytes in COL7A1 gene therapy of dystrophic epidermolysis bullosa. J Invest Dermatol 2006; 126: 766 - 772 .

14. Pageon H., Zucchi H., Asselineau D. Distinct and complementary roles of papillary and reticular fibroblasts in skin morphogenesis and homeostasis. Eur J Dermatol 2012; 22: 324-332.

15. Sorrell J. M., Baber M.A., Caplan A.I. Sitematched papillary and reticular human dermal fibroblasts differ in their release of specific growth factors/cytokines and in their interaction with keratinocytes. J Cell Physiol 2004; 200: 134-145.

16. Driskell R. R., Lichtenberger B. M., Hoste E. et al. Distinct fibroblast lineages determine dermal architecture in skin development and repair. Nature 2013; 504: 277-281.

17. Wang J., Dodd C., Shankowsky H. A. et al. Deep dermal fibroblasts contribute to hypertrophic scarring. Lab Invest 2008; 88 (12): 1278—1290. 
18. Varkey M., Ding J., Tredget E. E. Differential collagen-glycosaminoglycan matrix remodeling by superficial and deep dermal fibroblasts: potential therapeutic targets for hypertrophic scar. Biomaterials 2011; 32 (30): 7581-7591.

19. Varkey M., Ding J., Tredget E. E. Superficial dermal fibroblasts enhance basement membrane and epidermal barrier formation in tissue-engineered skin: implications for treatment of skin basement membrane disorders. Tissue Eng Part A 2014; 20 (3-4): 540-552.

20. Gawronska-Kozak B. Scarless skin wound healing in FOXN1 deficient (nude) mice is associated with distinctive matrix metalloproteinase expression. Matrix Biol 2011; 30 (4): 290_300.

21. Thangapazham R. L., Darling T. N., Meyerle J. Alteration of skin properties with autologous dermal fibroblasts. Int J Mol Sci 2014; 15 (5): 8407-8427.

22. Chen M., Woodley D. T. Fibroblasts as target cells for DEB gene therapy. J Invest Dermatol 2006;126 (4): 708-710.

23. Zorin V.L., Zorina A.I., Cherkasov V.R. Dermal'nye fibroblasty: chto novogo? Perspektivy klinicheskogo primeneniya. Kosmetika \& Meditsina 2010; 3: 28-33. [Зорин В. Л., Зорина А. И., Черкасов В.Р. Дермальные фибробласты: что нового? Перспективы клинического применения. Косметика \& Медицина 2010; 3: 28-33.]
24. Küttner V., Mack C., Gretzmeier C. et al. Loss of collagen VII is associated with reduced transglutaminase 2 abundance and activity. J Invest Dermatol 2014; 134 (9): 2381-2389.

25. Davidson J. M. Proteomic revelations. J Invest Dermatol 2014; 134 (9): 2301-2302.

26. Ortiz-Urda S., Lin Q., Green C. L. et al. Injection of genetically engineered fibroblasts corrects regenerated human epidermolysis bullosa skin tissue. J Clin Invest 2003; 111: 251—255.

27. Woodley D. T., Krueger G. G., Jorgensen C. M. et al. Normal and gene-corrected dystrophic epidermolysis bullosa fibroblasts alone can produce type VII collagen at the basement membrane zone. J Invest Dermatol 2003; 121: 1021-1028.

28. Kern J. S., Loeckermann S., Fritsch A. et al. Mechanisms of fibroblast cell therapy for dystrophic epidermolysis bullosa: high stability of collagen VII favors long-term skin integrity. Mol Ther 2009; 17 (9): 1605-1615.

29. Wong T., Gammon L., Liu L. et al. Potential of fibroblast cell therapy for recessive dystrophic epidermolysis bullosa. J Invest Dermatol 2008; 128: 2179-2189.

30. Nagy N., Almaani N., Tanaka A. et al. HB-EGF induces COL7A1 expression in keratinocytes and fibroblasts: possible mechanism underlying allogeneic fibroblast therapy in recessive dystrophic epidermolysis bullosa. J Invest Dermatol 2011; 131: 1771-1774.
31. Petrof G., Martinez-Queipo M., Mellerio J.E. et al. Fibroblast cell therapy enhances initial healing in recessive dystrophic epidermolysis bullosa wounds: results of a randomized, vehicle-controlled trial. Br J Dermatol 2013; 169: 1025-1033.

32. Venugopal S. S., Yan W., Frew J.W. et al. A phase II randomized vehicle-controlled trial of allogeneic fibroblasts for recessive dystrophic epidermolysis bullosa. J Am Acad Dermatol 2013; 10: 898-908.

33. Rouabhia M., Park H., Meng S. et al. Electrical stimulation promotes wound healing by enhancing dermal fibroblast activity and promoting myofibroblast transdifferentiation. PLOS One 2013; 8 (8): e71660.

34. Tanaka M., Misawa E., Yamauchi K. et al. Effects of plant sterols derived from Aloe vera gel on human dermal fibroblasts in vitro and on skin condition in japanese women. Clin Cosmet Investig Dermatol 2015; 8: 95-104.

35. Hashimoto K., Higashiyama S., Asada H. et al. Heparin-binding epidermal growth factor-like growth factor is an autocrine growth factor for human keratinocytes. J Biol Chem 1994; 269: 20060-20066.

36. Goishi K., Higashiyama S., Klagsbrun M. et al. Phorbol ester induces the rapid processing of cell surface heparin-binding EGF-like growth factor: conversion from juxtacrine to paracrine growth factor activity. Mol Biol Cell 1995; 6: 967-980.

об авторах:

В. И. Альбанова - д.м.н., ведущий научный сотрудник отдела дерматологии ФГБУ «ГНЦДК» Минздрава России, Москва

А. Э. Карамова — К.м.н., ведущий научный сотрудник отдела дерматологии ФГБУ «ГНЦДК» Минздрава России, Москва

В. В. Чикин — к.М.н., старший научный сотрудник отдела дерматологии ФГБУ «ГНЦДК» Минздрава России, Москва

А. А. Минеева — младший научный сотрудник отдела дерматологии ФГБУ «ГНЦДК» Минздрава России, Москва

\section{Конфликт интересов}

Авторы заявляют об отсутствии потенциального конфрликта интересов, требующего раскрытия в данной статье 